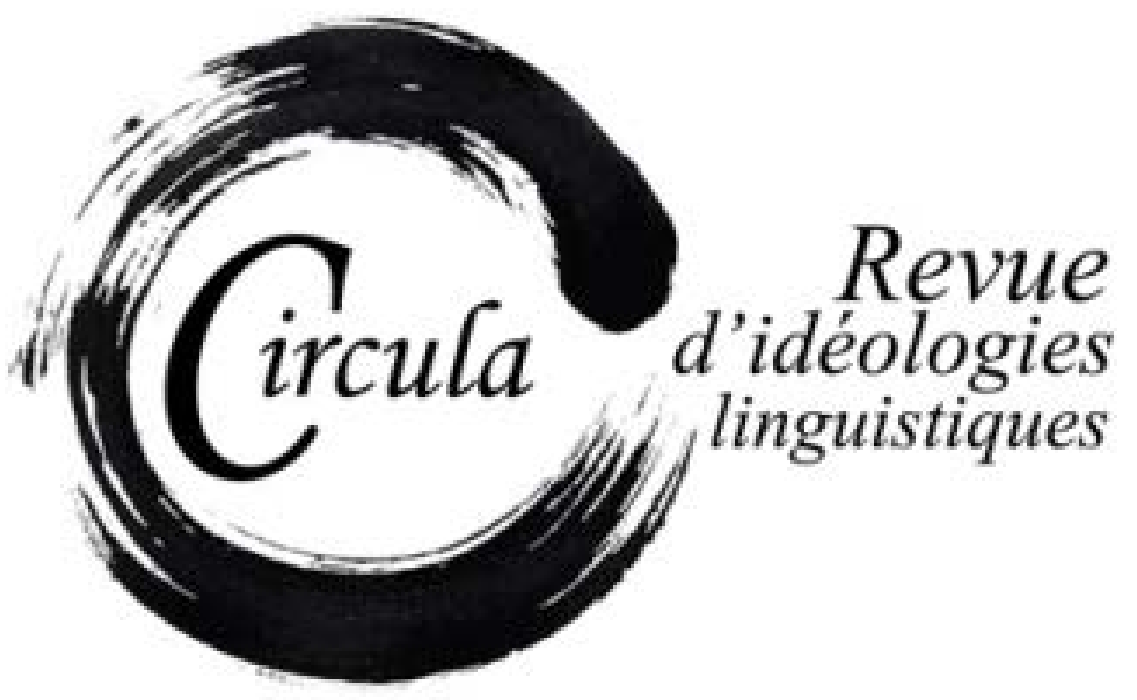

TITRE: ACADEMIA Y HABLANTES FRENTE AL SEXISMO LINGÜÍSTICO: IDEOLOGÍAS LINGÜÍSTICAS EN LA PRENSA ESPAÑOLA

Auteur(s): CARMEN LLAMAS SÁIZ, UNIVERSIDAD DE NAVARRA

RevUe: CiRCulA, NUMÉRO 1, PAGES 196-215

ISSN: 2369-6761

DiRECTEURS: Wim REMYSEN ET SABINE SCHWARZE

URI: HTTP://HDL.HANDLE.NET/11143/7995

DOI: $10.17118 / 11143 / 7995$ 


\title{
Academia y hablantes frente al sexismo lingüístico: ideologías lingüísticas en la prensa española ${ }^{1}$
}

\author{
Carmen Llamas Sáiz, Universidad de Navarra \\ cmllamas@unav.es
}

Resumen: Este trabajo analiza el modo en que la prensa española se hizo eco del debate en torno al sexismo lingüístico tras la publicación en marzo de 2012 del Informe de la RAE titulado "Sexismo lingüístico y visibilidad de la mujer”. El estudio se centra en las ideologías lingüísticas expresadas por Academia y hablantes en dos de los principales periódicos de España, El País y ABC; concretamente, se presta atención a los argumentos con que las distintas voces sustentan su opinión acerca del lenguaje sexista. Los ejes sobre los que gira el debate y se construyen discursivamente ideologías lingüísticas son, principalmente, a) el empleo del masculino genérico, b) el sentimiento de inclusión o exclusión en la lengua por parte de las mujeres y c) la consideración sexista de la lengua y de sus hablantes.

Palabras clave: ideologías lingüísticas; lenguaje sexista; análisis del discurso; discurso público

Abstract: This paper analyses how the Spanish press echoed the debate on linguistic sexism after the publication by the Spanish Royal Academy (RAE), in March 2012, of a Report entitled "Linguistic Sexism and visibility of women". The study focuses on language ideologies expressed by RAE and speakers in two major newspapers in Spain, El País and ABC; particular attention is paid to the reasons argued by those different voices in order to sustain their opinion on sexist language. The axes around which the debate is organized and language ideologies are discursively constructed are mainly a) the use of generic male, b) the feeling of inclusion or exclusion in language by the women and c) consideration of sexist language and its speakers.

Keywords: language ideologies; sexist language; discourse analysis; public discourse

1. Este trabajo se inscribe en el Proyecto de Investigación "Discurso público: estrategias persuasivas y de interpretación", desarrollado por el grupo GRADUN (Grupo Análisis del Discurso. Universidad de Navarra) en el seno del ICS (Instituto Cultura y Sociedad) de la Universidad de Navarra; y en el Proyecto "Metodología del Análisis del Discurso: propuesta de una lingüística del texto integral", subvencionado por el Ministerio de Ciencia e Innovación (ref. FFI2010-20416). 


\section{Introducción}

La prensa es un poderoso medio de difusión de actitudes valorativas que los hablantes muestran hacia las lenguas, en general, y hacia su propia lengua, en particular (v. DiGiacomo, 1999: 105). Las lenguas se evalúan con frecuencia y se consideran buenas o malas, modernas o anticuadas, impositivas o democráticas, sexistas o igualitarias, etc. Obviamente, aceptando también diferentes grados de valoración entre los polos. En todas estas actitudes se mezclan componentes afectivos y mentales, que, a su vez, pueden incluir propuestas de cambio lingüístico (v. Silverstein, 1985).

En general, los textos son un medio imprescindible para estudiar las ideologías lingüísticas, tanto desde un punto de vista discursivo como metadiscursivo:

The study of language ideologies [...] involves examining the texts and practices in which languages are represented - not only spoken and written but also spoken and written about. It is from these representations that language users learn how linguistic phenomena are conventionally understood in their culture (Cameron, 2003: 448).

Johnson y Milani (2010: 3) resaltan igualmente la importancia de determinados textos para el estudio de las ideologías lingüísticas; de hecho, en su opinión, una aproximación a este objeto de estudio "cannot be fully achieved without a close scrutiny of the texts, practices, and politics of mass mediation". En este sentido, el presente artículo se centra en las reacciones de las que la prensa se hizo eco tras la publicación de un informe de la Real Academia Española sobre el sexismo lingüístico y la visibilidad de la mujer en la sociedad. El tema generó gran polémica por las posturas encontradas entre quienes sostenían que la lengua española es sexista, machista o discriminatoria y quienes, como la Academia, afirmaban que esos adjetivos no tienen fundamento desde el punto de vista lingüístico - sin perjuicio de que, al hablar sobre una lengua, sea preciso considerar aspectos de carácter social.

Las distintas maneras de entender la relación entre la lengua y el uso que los hablantes hacen de ella sirven, en general, para conformar algunas ideologías lingüísticas:

[e]l hecho lingüístico total, el dato para la ciencia del lenguaje, es irreductiblemente dialéctico por naturaleza. Es una interacción mutua e inestable de formas de significación que están contextualizadas en situaciones de uso interesado por los humanos, y que está mediada por el fenómeno de la ideología cultural (Silverstein, 1985: 220).

Por lo que respecta al sexismo lingüístico, tener en cuenta esta interacción entre forma y contexto permitiría una comprensión abarcadora del tema; en otros términos, la perspectiva discursiva o pragmática daría cuenta de los distintos factores que intervienen en la configuración del género gramatical pero también en la producción e interpretación lingüísticas (v. Pérez García, 2007; Vigara Tauste, 2009; Márquez, 2013). Sin embargo, como se mostrará a través de los ejemplos, las opiniones 
presentadas en la prensa tienden a ofrecer una visión ciertamente simplificada de esta realidad, alejándose de puntos de vista integradores sobre el tema:

por ejemplo, puede considerarse al género no como categoría absoluta, sino como categoría mixta o pluridimensional, distinguiendo entre género propio de los sustantivos que designan seres inanimados y el de aquellos con referencia animada, especialmente personal. Igualmente, se puede sostener la vinculación entre género y sexo sin llegar a defender un isomorfismo entre estructuras lingüísticas y distinciones extralingüísticas (Márquez, 2013: 10).

En cualquier caso, cabe destacar que el informe de la Real Academia sobre el sexismo lingüístico presentaba una postura que no era nueva, sino que seguía "la línea de lo que se defiende en obras recientes como la Nueva gramática de la lengua española de 2009, el DRAE [...] o el Diccionario panhispánico de dudas" (Azofra Sierra, 2012a); sin embargo, la publicación tuvo un enorme eco en la prensa y en los días posteriores vio la luz un importante número de noticias, artículos de opinión y reportajes en los que, habitualmente con una fuerte carga valorativa, se aludía al tema del sexismo lingüístico. Como se ha apuntado al inicio de este artículo, la prensa es en la actualidad un medio decisivo para la difusión de opiniones de los hablantes hacia la lengua e, incluso, para la generación de determinadas ideologías lingüísticas.

Así, en los siguientes epígrafes nos ocuparemos, en primer lugar, del propio informe de la RAE, de las opiniones que defiende y de los argumentos que las sostienen; en segundo, de la caracterización del corpus y de la metodología empleada; y, por último, nos detendremos en los diversos textos periodísticos con el objetivo de mostrar las voces a las que la prensa da cabida y el modo en que se presentan las ideologías lingüísticas en torno al sexismo lingüístico.

\section{Fundamentos y alcance del informe de la RAE sobre el sexismo lingüístico}

El 4 de marzo de 2012 la prensa dio a conocer un informe del académico Ignacio Bosque titulado "Sexismo lingüístico y visibilidad de la mujer"2. En él se llevaba a cabo una revisión crítica de diversas guías de lenguaje no sexista publicadas hasta esa fecha en España por instituciones diversas como universidades, sindicatos y comunidades autónomas. Este informe fue suscrito por una parte importante de la RAE, aunque no por la totalidad de sus miembros 3 . Por otra parte, cabe destacar que no todas las guías que hasta ese momento habían visto la luz se incluyeron en el informe.

2. El informe puede consultarse en la web de la Real Academia Española, en el Boletín de información lingüística de la Real Academia Española (BILRAE) y lleva fecha de 1 de marzo de 2012.

3. En concreto, al final del documento se señala que el informe "ha sido suscrito por todos los académicos numerarios y correspondientes que asistieron al pleno de la Real Academia Española celebrado en Madrid el jueves, 1 de marzo de 2012". Se incluye asimismo el nombre de todos ellos.

4. Entre otras, no figuran la Guía de comunicación no sexista del Instituto Cervantes (2011), la Guía para un discurso igualitario en la Universidad de Alicante (s.f.), elaborada por Marimón y Santamaría o la Guía para el uso no sexista del lenguaje 
El debate acerca del llamado "sexismo lingüístico" se ha abordado desde perspectivas como la gramatical y la pragmático-discursiva, pero también desde un punto de vista social y sociológico. La bibliografía sobre el tema es ingente y no pretendemos aquí abarcarla en su totalidad ${ }^{6}$; sin embargo, es preciso destacar que el informe de la RAE se centra fundamentalmente en aspectos de carácter gramatical, mientras que la prensa recoge opiniones que no se ciñen exclusivamente a este ámbito e incluyen aspectos de diverso tipo (desigualdades económicas y sociales, relaciones de poder, sentimientos de exclusión, etc.). Dado que la prensa parte del documento de Ignacio Bosque, presentaremos a continuación algunos datos de carácter gramatical tratados por la bibliografía sobre el tema. El objetivo es doble: de un lado, se trata de situar los fundamentos y el alcance del informe de la Real Academia Española y, de otro, se pretende confrontar este documento con las distintas instancias discursivas que en la prensa se adhirieron a la postura académica, la rechazaron abiertamente o la criticaron de una manera u otra. En esta misma dirección, analizaremos brevemente algunas publicaciones de carácter lingüístico que, también como reacción al informe, vieron la luz en el mismo periodo de tiempo en que se sitúan los datos de prensa.

En un trabajo reciente titulado La evolución del género gramatical masculino como término genérico, Rodríguez Fernández (2009; v. asimismo Márquez, 2013: 10-11) considera que existen dos posturas contrapuestas en torno al sexismo lingüístico: la de la gramática funcional, que defiende la existencia de un masculino genérico que abarca, desde un punto de vista gramatical, el masculino y el femenino (v., por ejemplo, Roca, 2005a y b); y la de la crítica feminista del lenguaje, que considera que el masculino no recibe en ningún caso este tipo de interpretación en el uso de la lengua. Esta última postura, mantenida por diversas instancias en el discurso de la prensa, considera que las lenguas son el reflejo de una estructura social de tintes androcéntricos que discrimina a la mujer? ${ }^{7}$ La crítica feminista del lenguaje se enmarca en los denominados estudios de género (gender studies)", que a su vez suelen servir de punto de partida para las propuestas de cambio lingüístico de las guías del lenguaje no sexista. Dichas propuestas pueden agruparse como sigue (Azofra Sierra, 2012a):

en la Universitat Autònoma de Barcelona (2011), con propuestas para el catalán y el castellano, cuya autoría corresponde a Marçal, Kelso y Nogués.

5. Emplearemos generalmente esta denominación dado que, al ser utilizada con mayor frecuencia por la Real Academia Española, es la que más se repite en la prensa; no obstante, en la bibliografía se manejan otras como "discurso sexista", "lenguaje sexista", "uso sexista del lenguaje", "lenguaje igualitario", etc.

6. Pueden hallarse interesantes análisis y numerosas referencias bibliográficas en papel y en formato electrónico en los trabajos de Martínez Garcia (2008), Rodríguez Fernández (2009), Vigara Tauste (2009), Azofra Sierra (2010) o, más recientemente, en Lledó Cunill (2013) y en Márquez (2013).

7. Language and woman's place de Lakoff (1975) es la obra que da inicio a esta línea de estudio. Entre las publicaciones más recientes cabe destacar la editada por Holmes y Meyerhoff (2003).

8. Los diversos significados del término género son la base de algunas de las discusiones sobre el sexismo lingüístico que la prensa recoge. Desde una visión exclusivamente lingüística, se insiste en distinguir, de un lado, el significado de sexo biológico y, de otro, el de género gramatical o sexo semántico (v. Roca 2005a y b). 
1. Uso de desinencias para marcar el género femenino en todas las profesiones y cargos (la concejala, la jueza, la médica, etc.).

2. Empleo, en diversa medida, de dobletes (determinantes, nombres, determinantes y nombres) que abarquen el femenino y el masculino (todos y todas, los ciudadanos y las ciudadanas, etc.).

3. Preferencia por términos que hagan referencia a una colectividad (la ciudadanía, el profesorado, etc.).

4. Utilización de la arroba como nueva desinencia que incluya el femenino y el masculino (tod@s, amig@s, etc.).

Por otra parte, entre quienes defienden la existencia del masculino genérico, es posible hallar posturas divergentes: hay quienes creen que debería usarse en cualquier ámbito, género o estilo y quienes sugieren que la lengua ofrece distintas posibilidades que cabe elegir en función de la situación comunicativa. De este modo, los desdoblamientos (estimadas amigas y estimados amigos o los y las estudiantes, por ejemplo) serían recomendables al comienzo de un discurso o de una carta, así como en determinadas lenguas de especialidad como la administrativa o la jurídica, lenguas que Moreno Cabrera (2012) denomina lenguas cultivadas y que, en palabras de este autor, "reflejan la cultura, la ideología o la política de las sociedades que las proponen, desarrollan o modifican".

Moreno Cabrera (2012) considera oportuno, en cualquier caso, distinguir competencia y actuación, ya que, en su opinión, las recomendaciones de las guías se ceñirían exclusivamente al uso de la lengua, no a la competencia lingüística, que sería únicamente uno de los componentes que entran en juego en la actuación. Para este autor, y este es uno de los argumentos más recurrentes en las opiniones que la prensa plasma, no existe una gramática sexista, pero sí puede haber un discurso sexista ${ }^{9}$.

El informe de la RAE, por su parte, defiende el empleo del masculino genérico, al tiempo que critica expresamente el planteamiento y las propuestas de las guías de lenguaje no sexista. Así, Bosque (2012) señala lo siguiente:

- Los lingüistas no han participado, en general, en la confección de las guías de lenguaje no sexista (GLNS); además, contienen recomendaciones que contravienen la norma del español $(\S 2)^{10}$.

- La existencia de discriminación hacia la mujer en nuestra sociedad o de comportamientos verbales sexistas, que son premisas verdaderas, no deben llevar a la conclusión de que la gramática ha de explicitar sistemáticamente la relación entre género y sexo (§ 3 ).

9. Roca (2012), sin embargo, cree que el último fin de las GLNS, sea este declarado o no, es la introducción de cambios en el discurso habitual de los hablantes, entre ellos, el empleo de dobletes del tipo los alumnos y las alumnas. De este modo, el hablante de español podría llegar a considerar que el masculino es siempre un género marcado.

10. El número de los epígrafes corresponde al que se señala en el documento de Bosque (2012). 
- Aunque está firmemente asentado en el sistema gramatical español, las GLNS no suelen reconocer la existencia del masculino genérico. No obstante, es lógico aceptar, por estar totalmente extendida, la formación de pares morfológicos en los nombres de profesiones y cargos ( $\$ 5$ y 6$)$.

- $\quad$ Las GLNS no ofrecen, en general, soluciones a cuestiones lingüísticas (§ 7).

- Las propuestas de las guías no concuerdan con la lengua común, por lo que se sobrentiende que los cambios sugeridos han de afectar exclusivamente a determinados lenguajes (§8).

- $\quad$ Por último, la postura de la RAE se resume del siguiente modo (§ 11):

No creemos que tenga sentido forzar las estructuras lingüísticas para que constituyan un espejo de la realidad, impulsar políticas normativas que separen el lenguaje oficial del real, ahondar en las etimologías para descartar el uso actual de expresiones ya fosilizadas o pensar que las convenciones gramaticales nos impiden expresar en libertad nuestros pensamientos o interpretar los de los demás.

El informe fue objeto inmediato de críticas, a las que, como se verá infra, la prensa dio cabida por extenso; sin embargo, también fue apoyado en los propios diarios y en un manifiesto redactado por varios lingüistas ${ }^{11}$. Asimismo, no podemos dejar de mencionar aquí el soporte que dio la red a otros tantos análisis, estudios, comentarios, entrevistas, conferencias, etc., sobre el tema ${ }^{12}$. Como se verá, la discusión generada, sin ser nueva, dio lugar a diversos planteamientos ideológicos en los que, como todo lo que afecta a la lengua, confluyeron aspectos lingüísticos, sociológicos y psicológicos.

\section{Análisis de la prensa y metodología}

Para el estudio se han tomado todos aquellos textos publicados entre el 4 y el 19 de marzo de 2012 en las ediciones digitales españolas de El País y ABC. Los términos de búsqueda han sido lenguaje sexista, lenguaje no sexista y sexismo lingüístico, tanto si funcionaban como etiquetas en las versiones en línea de los periódicos como si se trataba de sintagmas en los propios textos. El corpus lo componen 31 textos (14 de El País y 17 de $A B C$ ).

El trabajo constituye la continuación de una investigación previa, centrada en el mismo corpus, en el que se analizaron y clasificaron, según la Teoría de la valoración (Hunston y Thompson, 2000; White, 2002; Martin y White, 2005), aquellos términos que expresaban actitudes lingüísticas hacia la lengua, los hablantes, las instituciones, etc., en el ámbito del afecto, la apreciación y el juicio (v. Lla-

11. Este manifiesto, titulado "Acerca de la discriminación de la mujer y de los lingüistas en la sociedad" y disponible en línea, fue redactado por Antonio Fábregas, Maria Carmen Horno Chéliz, Silvia Gumiel Molina y Luisa Martí.

12. Queremos al menos mencionar algunas de estas reacciones, disponibles todas ellas en línea, que circularon por la red en los días posteriores a la publicación del informe de Bosque: Bengoechea (2012), Demonte (2012), López Díez (2012), Mendívil (2012) y Reyes (2012). 
mas Saíz, 2013). Al término de aquel estudio, se creyó conveniente ahondar en la función discursiva de dichas actitudes así como en las instancias que las pronunciaban ${ }^{13}$ : ¿a qué voces da cabida la prensa sobre el tema del sexismo lingüístico?, ¿qué opinones se defienden?, ¿quién considera la lengua sexista, machista, inclusiva, etc.? En la prensa española las posturas sobre este tema, así como la argumentación implícita en el discurso del propio periodista, conforman un panorama complejo de ideologías lingüísticas que desbrozaremos en las siguientes páginas. La ideología puede entenderse, de un modo amplio, en el sentido planteado por Verschueren:

[...] constelación de creencias e ideas del sentido común, a veces normativas, relacionadas con algún(os) aspecto(s) de la "realidad" (social). La naturaleza de sentido común de las creencias y las ideas se manifiesta en el hecho de que son raramente cuestionadas, dentro de un grupo específico de gente en una sociedad o comunidad dada, en un discurso relacionado con la "realidad" de la que se trata a través de varios géneros de discurso. El que no sean cuestionadas significa que las creencias y las ideas son a menudo (aunque no siempre y no exclusivamente) llevadas a cabo implícitamente antes que formuladas explícitamente. Las redes construidas retóricamente o apoyadas ideológicamente sirven para enmarcar, dar validez o legitimar actitudes y acciones en el ámbito en el que son aplicables (Verschueren, 2002: 371-372).

Ahora bien, aun pudiendo extender esta comprensión amplia de la ideología a los aspectos lingüísticos, conviene tener en cuenta que la concepción de las ideologías lingüísticas tiende a ser más restrictiva. Para Silverstein (1979, citado por Kroskrity, 2012: 140), estas son "conjuntos de ideas sobre el lenguaje que son articulados por los usuarios como una racionalización o justificación de estructuras y usos lingüísticos percibidos" (la cursiva es mía). Por su parte, Cameron (2003: 447) insiste en la necesidad de entender las ideologías lingüísticas como representaciones del lenguaje más que como creencias o actitudes. Si bien, como veremos, estas últimas pueden llevarnos a las primeras. Por otra parte, las ideologías de carácter lingüístico abarcan diversos temas relacionados tanto con la identidad individual como con la identidad social de las personas que se expresan en una determinada lengua, el español en este caso. Así, el sexismo lingüístico como ideología se manifiesta en la prensa en esta doble vertiente individual y social de las lenguas.

Desde el punto de vista metodológico, se han tomado las distintas representaciones lingüísticas halladas en los textos y se han analizado los argumentos, explícitos o implícitos, que las sustentan. Asimismo, se ha señalado en cada caso la instancia que defiende una determinada ideología: persona individual, organismo, institución, colectivo, etc., y si dicha ideología se presenta de modo aislado, unida a otra representación similar o contrapuesta a otra(s), de tal modo que da lugar a una estructura contraargumentativa.

13. V. Johnson y Milani (2010) para el estudio de todos los actores sociales que expresan una determinada ideología lingüística y a los que la prensa da voz. 


\section{Ideologías lingüísticas en la prensa española}

La prensa refleja, principalmente, tal y como vimos supra, dos posturas encontradas en torno al sexismo lingüístico: por una parte, la de quienes defienden modificar determinados procedimientos lingüísticos con el fin de hacer más visible la presencia de la mujer en la sociedad y, por otra, la de quienes prefieren respetar la norma de la lengua y el uso del masculino genérico, excepto en aquellos casos de términos referidos a profesiones (Azofra Sierra, 2012a). En ambas posturas encontramos lo que Cameron (1995) denomina "doble discurso", ya que las afirmaciones sobre cómo debe ser una lengua expresan el deseo de controlar e imponer un orden en dicha lengua, pero al mismo tiempo presentan un anhelo por ordenar y controlar otras esferas.

Aunque es cierto que de fondo está la discusión sobre el masculino genérico como componente del sistema de la lengua, en la prensa española encontramos una comprensión amplia del sexismo lingüístico en la dirección que apunta Márquez:

Si adoptamos una perspectiva de análisis pragmalingüistica, consideraremos que el sexismo ha de explicarse teniendo en cuenta tanto el sistema de la lengua como el contexto de uso y, por tanto, las circunstancias sociales e históricas actuales presentes en la mentalidad de los hablantes (Márquez, 2013: 56).

Así, las distintas opiniones a las que los periódicos dan voz consideran elementos de carácter gramatical que componen la estructura de una lengua pero, en mayor medida, aspectos comunicativos, culturales y sociológicos. En general, se observa un debate en el que se pone sobre la mesa la opinión de una instancia, la Real Academia, a la que otras voces adhieren o refutan. Desde el punto de vista formal, las distintas opiniones se presentan, de un lado, en forma de citas directas o indirectas en las noticias o reportajes; de otro, en una primera persona en los artículos de opinión. Veamos a continuación cuáles fueron las líneas principales por las que discurrió el debate en el discurso de la prensa y sus actores más destacados, así como los argumentos aducidos con mayor frecuencia por las distintas partes.

Una de las principales discusiones fue la que se generó en torno a la pertinencia o no de aceptar el uso del masculino genérico para designar a los dos sexos. La prensa tiende a presentar dos posturas encontradas: la defendida por la RAE en su informe y la recogida en las guías para un lenguaje no sexista. Si se ahonda en el modo en que este debate queda plasmado periodísticamente, interesa analizar con qué argumentos se defiende cada punto de vista o, más exactamente, a qué argumentos tienen acceso quienes leen la prensa con el fin de hacerse una opinión sobre esta cuestión.

Debido a que el corpus se tomó a partir de la difusión del informe de la RAE en la propia prensa, la idea de aceptar el uso del masculino genérico para designar a los dos sexos, así como los argumentos que justifican este empleo, es la que aparece de manera más recurrente. Así, por ejemplo, en (1) el periodista hace suya la voz de la Academia y presenta de manera negativa a las personas respon- 
sables de las guías, señalando que se sienten molestas por el uso genérico del masculino. Se justifica la postura de la RAE a favor del empleo del masculino genérico por estar firmemente asentado en el sistema gramatical español y en el de otras lenguas. El argumento es, pues, lingüístico, fuera de cualquier otra consideración.

La contraargumentación se compone de tal modo que el marcador discursivo a pesar de que introduce con mayor fuerza el argumento de la RAE y presenta como injustificada la posición de las guías. Más adelante, la misma noticia mantiene esta dirección argumentativa: se muestra entrecomillada la opinión del académico Ignacio Bosque, quien hace hincapié, de nuevo por medio de estructuras refutativas introducidas por pero, en la insostenibilidad, la arbitrariedad y el sinsentido de propuestas como la de forzar las estructuras lingüísticas. Aunque aquí se ofrece un fragmento, la noticia aparecida en $A B C$ da voz principalmente a los argumentos aportados por el informe, no a los de las personas responsables de las guías, que están presentes en el texto, pero sin voz:

(1) A los responsables de estas guías les molesta de forma especial el uso genérico del masculino para designar a los dos sexos, a pesar de que "está firmemente asentado en el sistema gramatical español" y de otras muchas lenguas, y recomiendan, por ejemplo, decir "la ciudadanía”, en lugar de "todos los ciudadanos"; "las personas becarias", en vez de "los becarios", o "personas sin trabajo" y no "parados" [...]. Ante los argumentos de los lingüistas, los responsables de las guías podrían decir que sus recomendaciones proceden de "su sensibilidad ante la discriminación de la mujer en el mundo moderno". Pero ese argumento "es insostenible, puesto que califica arbitrariamente de sexista al grupo - absolutamente mayoritario - de mujeres y hombres con una sensibilidad diferente", afirma Bosque. [...] Bosque tiene claro que el propósito último de las guías de lenguaje no sexista es loable porque quieren "contribuir a la emancipación de la mujer y a que alcance su igualdad con el hombre en todos los ámbitos del mundo profesional y laboral", pero no tiene sentido "forzar las estructuras lingüísticas para que constituyan un espejo de la realidad" ni "impulsar políticas normativas que separen el lenguaje oficial del real”. (ABC, 4 de marzo 2012; las cursivas son nuestras) $)^{14}$

En otra noticia de este mismo medio, se insiste igualmente en la debilidad de los argumentos que arremeten contra el empleo del masculino genérico. De nuevo, la voz del académico Bosque es la que predomina como argumento de autoridad, frente a otras opiniones que, al parecer de la Academia, son insostenibles o están poco justificadas:

(2) La RAE considera "insostenible" la conclusión de estas guías de que "el léxico, la morfología y la sintaxis de nuestra lengua han de hacer explícita sistemáticamente la relación entre género y sexo, de forma que serán automáticamente sexistas las manifestaciones verbales que no sigan tal directriz, ya que no garantizarían "la visibilidad de la mujer". [... . Las guías proclaman, "de manera poco justificada" (RAE dixit), la discriminación en las expresiones nominales

14. Se marcan en cursiva aquellos términos o expresiones a los que se hace referencia en el análisis de los textos periodísticos presentados. 
construidas en masculino con la intención de abarcar los dos sexos. (ABC, 5 de marzo 2012; las cursivas son nuestras)

La opinión mantenida por el informe de la RAE es compartida por distintos autores a los que los periódicos dan voz. En un reportaje elaborado por el periodista Winston Manrique Sabogal para El País, se traen a colación los argumentos de quienes defienden el contenido del informe, como se aprecia en los siguientes fragmentos. En ellos se alude al sentido común de los hablantes y a la Academia como autoridad que dicta unas normas que facilitan la comunicación. Las indicaciones de las guías se ven como una imposición política que, de un modo intrusivo, manipulan la lengua:

(3) [Ana Caballé, escritora y profesora de la Universidad de Barcelona] muestra su gratitud por el informe de Ignacio Bosque por haber llamado la atención sobre un fenómeno "que va en contra del sentido común de los hablantes". Se han puesto los puntos sobre las íes.

Indudablemente, recuerda César Antonio de Molina, director de la Casa del Lector y exministro de Cultura, "la lengua es un ser vivo, que añade, quita, inventa y es la Academia la que se dedica al estudio de esto, por lo tanto, hay que acatar sus normas porque sino [sic] viviríamos en una selva". [...]

Para la escritora Elvira Lindo, "todo el mundo en España entiende que nuestra lengua diferencia entre sexo y género, por tanto, hay sustantivos de apariencia masculina en los que sabemos que están incluidas también las mujeres. Forzar otra manera en el habla es ni más ni menos una imposición política, que nada tiene que ver con las reglas filológicas ni con el uso natural del habla. [...] Creo que nuestro país aún tiene mucho camino por recorrer en este sentido, pero censurar y manipular la lengua de los ciudadanos es ridículo e intrusivo. Son los políticos los que generalmente popularizan todas estas tonterías". (El País, 5 de marzo 2012; las cursivas son nuestras)

Frente a la postura de la Academia, muy crítica con la fundamentación de las opiniones contrarias, los periódicos dan también cabida a otras instancias discursivas que ven en el empleo del masculino genérico un modo de excluir a la mujer como referente de determinados términos en el discurso. En el siguiente pasaje, por ejemplo, la opinión de la Academia se contrasta con la de Inés Alberdi, catedrática de sociología y autora de uno de los artículos de opinión de El País publicado el día 5 de marzo. En él, Alberdi señala que la lengua española oscurece y olvida la presencia de la mujer en cualquier colectivo ${ }^{15}$.

(4) En sus argumentos contra las guías se refiere [la RAE] casi exclusivamente a una de las cuestiones que estas señalan, la necesidad de hacer manifiesta la presencia femenina en cualquier colectivo al que nos estemos refiriendo, niñas y niños, padres y madres, cuestión que la lengua española oscurece a través del uso del genérico masculino. [...] Este es quizá el aspecto más difícil de revisar si queremos que el español no olvide a las mujeres, pero hay

15. Véase este ejemplo en relación con el fragmento (8), en el que se maneja esta misma metáfora al hablar de la invisibilidad de la mujer en el discurso. 
muchos otros. [...] No se trata tanto de señalar con el dedo a los que abusen del genérico masculino, como tratar de enseñar a todos a hablar con mayor rigor y respeto a la igualdad de género. (Inés Alberdi, “Pero, ¿dónde estaba la RAE?”, El País, 5 de marzo 2012; las cursivas son nuestras)

La discusión sobre el uso del masculino genérico en español suele girar en torno al concepto de inclusión de la mujer en el discurso ${ }^{16}$. Este término, así como su contrario y los derivados de ambos, se maneja con llamativa mayor frecuencia en los argumentos que sobre la cuestión presenta El País que en los ofrecidos por ABC. La relación es de 3 a 1. Para quienes apoyan las tesis defendidas por el informe, el masculino siempre tendrá un carácter genérico y, por tanto, en su empleo la mujer siempre habrá de sentirse incluida; sin embargo, en el polo contrario, se presentan las voces de mujeres que se sienten excluidas si en el discurso los términos masculinos se emplean de modo genérico. Se aprecia así que en estos casos no importa tanto el punto de vista gramatical como el social y comunicativo; esto es, la percepción que tanto mujeres como hombres, aunque especialmente las primeras, puedan tener ante el uso de la lengua ${ }^{17}$.

Por otra parte, este sentimiento de inclusión o exclusión lleva a caracterizar la propia lengua española como no inclusiva. En los siguientes fragmentos es posible reconocer estas actitudes lingüísticas en boca de diferentes personas. En (5), un artículo de opinión en el que Amparo Moreno, catedrática de Historia de la Comunicación, habla de este sentimiento de inclusión a partir del empleo del masculino, se distingue con claridad que la aceptación de un punto de vista gramatical no niega una perspectiva más pragmática del lenguaje, en la que tienen cabida otros elementos que atañen a la interpretación de los discursos. Esta doble perspectiva se construye mediante una estructura contraargumentativa con pero:

(5) Por mi parte, la lectura atenta de numerosos textos me condujo a constatar que el masculino, tal como lo utilizamos en los debates públicos académicos, políticos y periodísticos, no abarca a las mujeres y tampoco a todos los hombres porque solo considera humano el arquetipo viril.

Por eso las mujeres nos podemos sentir incluidas en los masculinos, porque estamos donde queremos estar. Pero algunas los evitamos, conscientes de que afectan al objetivo de la cámara que utilizamos, reducen el enfoque sobre los seres humanos, dejan fuera parte de las

16. El hecho de que el masculino tenga la posibilidad de funcionar como genérico no implica que siempre tenga esa interpretación. Márquez (2013: 125) cree que se da una referencia genérica si se cumplen dos requisitos: a) el hablante tiene la intención de hacer una referencia no específica: universal (a ambos sexos) o prototípica (a cualquiera de ellos) y b) la realidad extralingüística muestra como posible la aparición de ambos sexos (ambos o cualquiera de ellos) en el ámbito referencial de que se trate. Para esta autora, "históricamente, se ha usado el masculino 'teóricamente' universal para hacer referencias específicas. Y es ese uso abusivo del masculino 'genérico' y no el uso extensivo en sí mismo el que es denunciable".

17. Precisamente a esta cuestión se refería Moreno Cabrera (2012) en sus Reflexiones críticas sobre el informe de la RAE. El autor afirmaba que aunque no existe una gramática sexista, sí puede haber un discurso sexista. 
relaciones sociales, borran matices, crean la ilusión óptica de que vemos lo universal y nos llevan a confundir lo particular con lo general. Y buscamos otras imágenes y palabras adecuadas a unas sociedades plurales y complejas que queremos cambiar para hacerlas justas y equitativas. (Amparo Moreno, "Sexismo lingüístico: de la punta del iceberg al glaciar", El País, 13 de marzo 2012; las cursivas son nuestras)

En el siguiente ejemplo (6), Milagros del Corral, exdirectora de la Biblioteca Nacional, afirma no sentirse excluida de ninguna forma gramatical. Esto es así porque, al contrario de la posición defendida por Moreno en el discurso anterior, esta autora considera que el sentimiento de inclusión o exclusión de la mujer en determinadas formas lingüísticas proviene de la confusión entre biología y gramática. Esto es, desde una perspectiva estrictamente gramatical, los sentimientos de inclusión o exclusión no se consideran bases sólidas sobre las que construir la opinión. De hecho, cambios en el uso de la lengua como los propuestos por las guías son considerados por la autora "un sinsentido":

(6) Digo, pues, no a la discriminación de la mujer en cualquiera de las muchas modalidades en que ésta aún se produce. Y mi no es un no rotundo.

Sin embargo, esta reciente costumbre de pervertir nuestra maravillosa lengua castellana me parece un puro sinsentido. Nunca me he sentido excluida de forma gramatical alguna, singular o plural, ni creo que los hombres se sientan discriminados al ser aludidos, en singular y en plural, como artistas, periodistas, trapecistas, etcétera. Sin duda aquí se ha producido un error, aunque haya sido con la mejor intención. Aquí se ha confundido sexo con género, biología con gramática, gimnasia con magnesi. (Milagros del Corral, "No veo qué ganamos las mujeres", El País, 5 de marzo 2012; las cursivas son nuestras)

Por su parte, Elvira Lindo, escritora y columnista de El País, resta importancia al sentimiento de inclusión o exclusión en el uso del masculino. En su opinión, no puede ser la base sobre la que discutir acerca de la discriminación de la mujer en la sociedad:

(7) No quiero que sindicatos, centros laborales dependientes de un ministerio o comunidades autónomas, etcétera, presionen a trabajadores o aspirantes a utilizar el lenguaje de determinada manera. Son tan fundamentales los aspectos que las mujeres deseamos mejorar que, francamente, estar incluida en un plural masculino que se entiende como genérico me importa bien poco. (Elvira Lindo, “Quiero", El País, 7 de marzo 2012; las cursivas son nuestras)

Por último, en algunos textos periodísticos se alude al concepto de inclusión no desde el sentimiento de quien habla sino desde la constatación de que la lengua española no es inclusiva y no hace visibles a las mujeres porque no las representa. El lenguaje y el habla, entendidos aquí como una unidad, son para Carmen Plaza una actitud y un comportamiento social, que pueden dar o quitar protagonismo a las mujeres: 
(8) La desigualdad entre mujeres y hombres está enraizada en las actitudes y comportamientos sociales, afirma Carmen Plaza, directora general para la lgualdad de Oportunidades del Ministerio de Sanidad y Servicios Sociales e Igualdad. "Uno de ellos es la representación social de las mujeres y el lenguaje es una forma de representarlas. Siempre se ha defendido la necesidad de que las mujeres se hagan visibles, también en el habla. Nombrarlas es una manera de asignarles un lugar en la sociedad, de darles el protagonismo que a lo largo de los últimos años han ido adquiriendo. De ahí la necesidad de usar un lenguaje que se ha llamado inclusivo, siempre desde el respeto a la gramática". (El País, 5 de marzo 2012; las cursivas son nuestras)

En el fragmento del periodista Antonio Astorga que se reproduce a continuación se repite el argumento de la inclusión de la mujer en el lenguaje en dos discursos diferentes, el de la consejera andaluza de Igualdad y el del sindicato Comisiones Obreras. La consejera habla de la necesidad de "caber" en el lenguaje; mientras que desde CC.OO. se pide a la RAE que promueva un empleo inclusivo e igualitario de la lengua española:

(9) Otros aludidos acuchillaban al amanecer y al atardecer el informe de la RAE. La consejera andaluza de Igualdad, Micaela Navarro replicaba que "en la Gramática de la RAE tenemos que caber todos y todas”; Comisiones Obreras remitía una carta, firmada por Carmen Bravo, a Ignacio Bosque demandando a la RAE que promueva "un uso de la lengua más inclusivo desde el punto de vista del género y más igualitario desde la práctica democrática del lenguaje”. (ABC, 6 de marzo 2012; las cursivas son nuestras)

En otras ocasiones, se presenta en los textos un parecer contrario no tanto al contenido del informe de la RAE como a la actitud impositiva hacia la lengua que esta institución pudiera tener. Es el caso del siguiente artículo de Manrique Sabogal en El País, en el que se citan unas palabras de Javier Marías, escritor y académico:

(10) "Es que el lenguaje es lo único que tenemos todos, lo que tiene cada uno para seguir hablando, comunicarse, expresarse. El lenguaje es lo más democrático que existe”, reflexiona Javier Marías, escritor y académico que en muchas ocasiones se ha referido a este tema incluso en sus libros. Por todo eso, agrega Marías, "lo sentimos como algo irrenunciable y no aceptamos manipulaciones ni dirigismos de ninguna índole ni procedencia. Ni de la Academia ni de instituciones ajenas. Los cambios que vengan serán acordes con su evolución natural. El dirigismo de la lengua no tendrá éxito porque cualquier imposición en ella la vemos como una intromisión intolerable en nuestro [sic] habla y en nuestro pensamiento; como un atentado a nuestra verdadera libertad". (El País, 6 de marzo 2012; las cursivas son nuestras)

El sentimiento de inclusión no es el único que se trae a colación en el debate sobre el sexismo lingüístico en la prensa española. El desprecio, la ofensa o la pasión, entre otros, se toman como argumentos para justificar determinadas posturas. Así, por ejemplo, la humillación y la ofensa se 
presentan en la prensa como actitudes que determinados colectivos sienten hacia el Diccionario de la Real Academia Española (DRAE) y, por ende, hacia quienes componen la institución que lo ha confeccionado:

(11) El Diccionario de la Real Academia Española (DRAE) es para muchos un memorial de agravios. Asociaciones de pacientes, organizaciones feministas, partidos políticos y militantes homosexuales se declaran humillados y ofendidos por el libro. (ABC, 5 de marzo 2012; las cursivas son nuestras)

Desde el punto de vista discursivo, y en el marco de la Teoría de la valoración, es importante destacar lo que a este respecto apunta White (2002): al expresar el afecto ante los objetos, sucesos o ante las personas, el autor del discurso quiere compartir una actitud emocional y provocar en el receptor una respuesta empática. Esta empatía, como ya señalaba la retórica clásica, puede funcionar de marco para lograr el acuerdo ideológico, que es lo que está en juego en la discusión acerca del sexismo lingüístico. A diferencia del caso anterior, en (12) la expresión del afecto posee carácter autoral. El catedrático de lengua española y miembro de la Real Academia pide, a través de una primera persona del plural inclusiva, que la discusión sobre el sexismo lingüístico se desdramatice, es decir, pide que el debate no se sustente en ningún tipo de sentimiento sino en razones de tipo lingüístico, como expone a continuación:

(12) Desdramaticemos las cosas. No es el masculino el único elemento no marcado del sistema gramatical. Igual que en español hay dos géneros (en otras lenguas hay más, o hay solo uno), hay también dos números, singular y plural (en otras hay más, o solo uno), y el singular es el número no marcado frente al plural. Así, del mismo modo que el masculino puede asumir la representación del femenino, el singular puede asumir la del plural. (Pedro Álvarez de Miranda, "El género no marcado", El País, 7 de marzo 2012; las cursivas son nuestras )

En efecto, como puede comprobarse en los casos que siguen, la discusión en torno a los temas lingüísticos, entre los que se incluye el del sexismo, puede articularse en torno al afecto pasional:

(13) Por qué la lengua levanta pasiones

Pasión. Mucha pasión. Eso es lo que más ha ido incorporando la lengua castellana o española a su ADN y al de sus hablantes a la hora de referirse a ella. Ese es el verdadero hilo que la recorre a lo largo de sus mil años con quienes la utilizan y a quienes sirve [...]. (El País, 6 de marzo 2012; las cursivas son nuestras)

(14) Un tema [el del sexismo lingüístico] que ha trenzado las diferentes pasiones que suelen despertar las cuestiones relacionadas con el idioma [...]. (El País, 12 de marzo 2012; las cursivas son nuestras) 
Así pues, a tenor de lo expuesto, es posible afirmar que el debate sobre el lenguaje sexista se articula en el discurso de la prensa principalmente sobre dos ejes: el de la aceptación o rechazo del masculino genérico y el del sentimiento de inclusión o exclusión en la lengua por parte de las mujeres. Un tercer eje muy importante, y que subsume los dos anteriores, es el de la consideración sexista o no sexista de la lengua española. El adjetivo sexista se aplica siempre de manera explícita a la lengua y de modo explícito e implícito a los hablantes de español. En el siguiente texto, las palabras de la escritora y articulista Rosa Montero, que se reproducen literalmente, consideran explícitamente sexista tanto al lenguaje como a la sociedad:

(15) Rosa Montero lo ha escrito admirablemente: "Es verdad que el lenguaje es sexista, porque la sociedad también lo es". Lo que resulta ingenuo, además de inútil, es pretender cambiar el lenguaje para ver si así cambia la sociedad. Lo que habrá que cambiar, naturalmente, es la sociedad. (El País, 7 de marzo 2012; las cursivas son nuestras)

Evidentemente, existe una diferencia entre acusar a un hablante de sexista y calificar la lengua de sexista. Esta distinción entra de lleno precisamente en el problema que plantea la discusión acerca del sexismo lingüístico. Así, en el análisis del discurso periodístico es importante distinguir si el adjetivo sexista se aplica indistintamente a lengua y hablantes o si este juicio posee un referente claro. El adjetivo sexista aplicado a la lengua es muy frecuente en todos los textos del corpus. En general, se pone en boca de quienes han elaborado las guías, pero igualmente en el de otras instancias que tienen la impresión de que el lenguaje puede considerarse sexista:

(16) Trece páginas contiene la guía de lenguaje no sexista de la Unidad de Igualdad de la Universidad de Granada (UGR). Compuesta por trece páginas, se presentó como "un vehículo ante las dudas que puedan surgir" y con la intención de que sirva para "fomentar la eliminación del lenguaje sexista todavía muy presente en nuestra sociedad y en la comunidad universitaria de Granada". (ABC, 7 de marzo 2012; las cursivas son nuestras)

(17) La lengua es hija de la historia y por ello no debe sorprendernos que la española sea tan sexista. Casi todas las lenguas lo son e incluso el inglés, que tiene mayor flexibilidad para adaptarse a los tiempos actuales, permite usos que reflejan la superioridad de lo masculino en nuestra cultura. (Inés Alberdi, “Pero, ¿dónde estaba la RAE?", El País, 5 de marzo 2012; las cursivas son nuestras)

(18) [E]l lingüista y catedrático de la Universidad de Alicante Félix Rodríguez, autor del Diccionario gay-lésbico (Gredos), sostiene que el DRAE rezuma homofobia cuando "se equipara pederastia y homosexualidad". "El castellano académico sigue siendo (aunque cada vez menos) una lengua sexista, machista y homófoba en la medida que sus hablantes lo son, pues la lengua siempre es un reflejo de la sociedad". (ABC, 4 de marzo 2012; las cursivas son nuestras) 
(19) Las portavoces de la Comisión de Igualdad en el Congreso del PP, PSOE, CiU e IP señalaban a la RAE que "el lenguaje debe evolucionar como la sociedad y abandonar tintes sexistas". (El País, 6 de marzo 2012; las cursivas son nuestras)

Estos cuatro ejemplos dejan entrever una determinada ideología lingüística al relacionar la lengua con la sociedad o con la historia y presentar a la primera como un reflejo del desarrollo histórico-social. La lengua es sexista porque la sociedad lo ha sido durante siglos. En realidad, son textos en los que los argumentos más lingüísticos presentados en los primeros ejemplos no parecen interesar.

Por último, se ha encontrado un texto en el que la lengua se representa como configuradora del pensamiento, tal y como expresa en una noticia la secretaria de igualdad de un sindicato. Tomando esta afirmación como ley de paso, se concluye que el pensamiento de la población es sexista dado que la lengua española lo es:

(20) No en vano "el lenguaje es el elemento que más influye en la formación del pensamiento en el ser humano, lo que deriva en la construcción de esquemas mentales, estereotipos y conceptos abstractos con los que nos desenvolvemos en la vida diaria”, explica Nuria Manzano, secretaria de Igualdad UGT-Madrid. Por lo tanto, un habla sexista influirá en tener un pensamiento sexista. Deja claro que "no es posible justificar la utilización de un lenguaje sexista en las tradiciones. Cuando las tradiciones son injustas hay que cambiarlas". (El País, 5 de marzo 2012; las cursivas son nuestras)

\section{Conclusiones}

En el presente trabajo se han destacado algunas de las ideologías lingüísticas - entendidas estas como representaciones de una lengua (v. Cameron, 2003) - que la prensa plasma y difunde en noticias y artículos. La investigación ha partido de un corpus de textos periodísticos en torno al sexismo lingüístico que, a pesar de no ser excesivamente amplio, ha logrado poner de relieve ideologías de diversa naturaleza acerca del lenguaje y las lenguas. En primer lugar, la identificación por parte del hablante entre la palabra y su referencia, que estaría en el origen de la aceptación o rechazo del masculino genérico. No siempre se acepta, como se ha mostrado en los ejemplos, que un término masculino desde el punto de vista gramatical pueda tener una referencia a ambos sexos o a cualquiera de ellos.

Por otra parte, la lengua se concibe, en palabras de algunas instancias a las que da voz la prensa, como "una actitud y un comportamiento social". Esta actitud y este comportamiento pueden tener un carácter inclusivo o exclusivo hacia las mujeres. Hablar de un modo considerado sexista no incluye a las mujeres en el discurso, por lo que estas se sienten desplazadas dentro de un determinado comportamiento social - igual que pueden sentirse no incluidas en otro tipo de actividades. En este sentido, hallamos aquí un doble discurso: existe una concepción de la lengua como una acción 
social que puede cambiarse, al tiempo que este posible cambio en lo lingüístico afectaría a otras esferas sociales.

Por último, el lenguaje se representa, especialmente para los lingüistas, como un sistema en el que funcionan abstracciones del tipo masculino y femenino, mientras que para un buen número de hablantes, al menos por lo que se colige de las instancias a las que la prensa da cabida, la lengua no es una abstracción, sino una realidad que se percibe en el hablar. Esta conceptualización coincide, no obstante, con un presupuesto comúnmente aceptado por los lingüistas: el habla es la realización de la lengua y la lengua no es sino la generalización y sistematización de los actos de hablar (v. Coseriu, 1981: 77).

Así pues, se comprueba que hay ocasiones, como la de la discusión en torno al sexismo lingüístico, en que la prensa ofrece múltiples ideologías lingüísticas defendidas por diversas instancias sociales. Evidentemente, el estudio sobre dichas ideologías en prensa ofrece, desde un punto de vista prospectivo, otras posibilidades como la comparación entre las ideologías aquí esbozadas y otras que pudieran revelarse en épocas o situaciones diferentes o la investigación más exhaustiva del origen de algunas de las representaciones lingüísticas ampliamente extendidas entre los hablantes, algo que supera con creces el objetivo planteado al inicio de estas páginas. 


\section{Bibliografía}

Azofra Sierra, Maria Elena (2010), "Sobre el género gramatical y sus implicaciones sociológicas", en Montserrat Huguet y Carmen González Marín (eds.), Historia y pensamiento en torno al género, Madrid, Dykinson, p. 267-294.

Azofra Sierra, Maria Elena (2012a), "Género gramatical y sexismo lingüístico (I)", disponible en http://morflog.hypotheses.org/482. [Sitio consultado el 20 de marzo de 2014.]

Azofra Sierra, Maria Elena (2012b), "Género gramatical y sexismo lingüístico (II)", disponible en http://morflog.hypotheses.org/541. [Sitio consultado el 20 de marzo de 2014.]

Bengoechea, Mercedes (2012), "La sociedad cambia, la Academia, no", disponible en http://blogs.elpais.com/mujeres/2012/03/el-informe-de-la-rae-el-error-humano-y-la-evolución-de-las-lenguas.html. [Sitio consultado el 20 de marzo de 2014.]

Bosque, Ignacio (2012), "Sexismo lingüístico y visibilidad de la mujer", disponible en http://www.rae.es/sites/default/files/Sexismo_linguistico_y_visibilidad_de_la_mujer_0.pdf. [Sitio consultado el 20 de marzo de 2014.]

Cameron, Deborah (1995), Verbal Hygiene, Londres/Nueva York, Routledge.

Cameron, Deborah (2003), "Gender and Languages Ideologies”, en Janet Holmes y Miriam Meyerhoff (eds.), The Handbook of Language and Gender, Malden (MA), Wiley-Blackwell, p. 447-467.

Coseriu, Eugenio (1981), Lecciones de lingüística general, Madrid, Gredos. [Título original: Lezioni di linguistica generale, Torino, Boringhieri, 1973. Versión española de José Maria Azáceta y García de Albéniz, revisada y, en parte, reelaborada por el autor.]

Demonte, Violeta (2012), "Las academias no hacen falta para la unidad del idioma", disponible en http://www.rebelion.org/noticia.php?id=146959. [Sitio consultado el 20 de marzo de 2014.]

DiGiacomo, Susan M. (1999), "Language ideological debates in an Olympic city: Barcelona 1992-1996”, en Jan Blommaert (ed.), Language ideological debates, Berlín, Mouton de Gruyter, p. 105-142.

Fábregas, Antonio, Maria Carmen Horno Chéliz, Silvia Gumiel Molina y Luisa Martí (2012), "Acerca de la discriminación de la mujer y de los lingüistas en la sociedad", disponible en http://manifiestolinguistica.weebly.com. [Sitio consultado el 20 de marzo de 2014.]

Holmes, Janet y Miriam Meyerhoff (2003), The Handbook of Language and Gender, Malden (MA), Wiley-Blackwell.

Hunston, Susan y Geoffrey Thompson (eds.) (2000), Evaluation in text: authorial stance and the construction of discourse, Oxford, Oxford University Press.

Instituto Cervantes (2011), Guía de comunicación no sexista, Madrid, Aguilar.

Johnson, Sally y Tommaso M. Milani (2010), Language ideologies and media discourses: texts, practices, politics, Londres/Nueva York, Continuum International Publishing Group. 
Kroskrity, Paul V. (2012), "El habla utilizada en la kiva de los tewas de Arizona como manifestación de una ideología dominante", en Bambi B. Schieffelin, Kathryn A. Woolard y Paul V. Kroskrity (eds.), Ideologías lingüísticas: práctica y teoría, Madrid, Catarata, p. 139-163. [Título original: Language ideologies: Practice and theory, Oxford, Oxford University Press, 1998. Traducción de Susana Castillo, Lorena Hernández, Vítor Meirinho y Laura Villa.]

Lakoff, Robin (1975), Language and woman's place, Nueva York, Harper \& Row.

Llamas Saíz, Carmen (2013), "La actitud ante la lengua en el discurso de la prensa española: léxico y argumentación a propósito del sexismo lingüístico”, en Carmen Llamas Saíz, Concepción Martínez Pasamar y Manuel Casado Velarde (eds.), Léxico y argumentación en el discurso público actual, Fráncfort del Meno, Peter Lang, p. 187-208.

Lledó Cunill, Eulàlia (2013), Cambio lingüístico y prensa: problemas, recursos y perspectivas, Barcelona, Laertes.

López Díez, Pilar (2012), "Dice la RAE que está por la igualdad entre hombres y mujeres: sobre el Informe Sexismo lingüístico y visibilidad de la mujer", disponible en http://www.mujeresenred.net/spip.php?article1952. [Sitio consultado el 20 de marzo de 2014.]

Marimón Llorca, Carmen e Isabel Santamaría Pérez (s.f.), Guía para un discurso igualitario en la Universidad de Alicante, Alicante, Vicerrectorado de Relaciones Internacionales.

Marçal, Heura, Fiona Kelso y Mercè Nogués (2011), Guía para el uso no sexista del lenguaje en la Universitat Autònoma de Barcelona, Barcelona, Servicio de Publicaciones de la Universitat Autónoma de Barcelona.

Márquez, María (2013), Género gramatical y discurso sexista, Madrid, Síntesis.

Martin, James R. y Raymond P. White (2005), The Language of Evaluation: Appraisal in English, Basingstoke, Palgrave Macmillan.

Martínez García, José Antonio (2008), El lenguaje de género y el género lingüístico, Oviedo, Ediciones de la Universidad de Oviedo.

Mendívil, José-Luis (2012), "No permita que el sexo de los árboles le impida ver el género del bosque", disponible en https://zaragozalinguistica.wordpress.com/2013/03/20/no-permita-queel-sexo-de-los-arboles-le-impidan-ver-el-genero-del-bosque. [Sitio consultado el 20 de marzo de 2014.]

Moreno Cabrera, Juan Carlos (2012), “Acerca de la discriminación de la mujer y de los lingüistas en la sociedad: reflexiones críticas”, disponible en http://infoling.org/repositorio/MORENOSEXISMO. pdf. [Sitio consultado el 20 de marzo de 2014.]

Pérez García, Ángela (2007), "Sexismo lingüístico: una aproximación a los estudios y métodos”, en Pilar Fernández Martínez y Amalia Pedrero González (eds.), La mujer y la sociedad de la información: ¿existe un lenguaje sexista?, Madrid, Fragua, p. 177-205. 
Reyes, Pedro (2012), "Lenguaje sexista y RAE", disponible en http://www.nuevatribuna. es/opinion/pedro-reyes/lenguaje-sexista-y-rae-el-rbol-que-no-permite-ver-el-bosque/20120306123348071470.html. [Sitio consultado el 20 de marzo de 2014.]

Roca, Ignacio (2005a), "La gramática y la biología en el género del español (1' parte)", Revista de la Sociedad Española de Lingüística, año 35, nº 1, p. 17-44.

Roca, Ignacio (2005b), "La gramática y la biología en el género del español ( $2^{2}$ parte)", Revista de la Sociedad Española de Lingüística, año 35, n² 2, p. 397-432.

Roca, Ignacio (2012), "Algunas reflexiones críticas sobre Acerca de la discriminación de la mujer y de los lingüistas en la sociedad", disponible en http://stel.ub.edu/linguistica-ub/webfm_send/55. [Sitio consultado el 20 de marzo de 2014.]

Rodríguez Fernández, María (2009), La evolución del género gramatical masculino como término genérico: su reflejo en la prensa española, Madrid, Fundamentos.

Silverstein, Michael (1985), "Language and the culture of gender: at the intersection of structure, usage and ideology", en Elisabeth Mertz y Richard J. Parmentier (eds.) Semiotic Mediation: sociocultural and psychological perspectives, Orlando, Academic Press, p. 219-259.

Verschueren, Jef (2002), Para entender la pragmática, Madrid, Gredos. [Título original: Understanding Pragmatics, London/New York, Arnold/Oxford University Press, 1999. Traducción de Elisa Baena y Marta Lacorte.]

Vigara Tauste, Ana M.a (ed.) (2009), “De sexismo, lenguaje, discurso y discriminación de género”, en Ana M. a Vigara Tauste (ed.), De igualdad y diferencias: diez estudios de género, Madrid, Huerga y Fierro.

White, Raymond P. (2002), "Appraisal: the language of evaluation and stance", en Jef Verschueren, Jan-Ola Östman, Jan Blommaert y Chris Bulcaen (eds.), The Handbook of Pragmatics, Amsterdam, John Benjamins, p. 14-36. 